\title{
Budget impact analysis of apixaban to treat and prevent venous thromboembolism in Italy
}

\author{
Marco Bellone ${ }^{1}$, Roberto Di Virgilio ${ }^{2}$, Paolo Di Rienzo ${ }^{3}$ \\ AdRes HE \& OR, Turin, Italy \\ Pfizer Italy, Rome, Italy \\ 3 Bristol-Myers Squibb Italy, Rome, Italy
}

\section{ABSTRACT}

BACKGROUND: Venous thromboembolism (VTE), a collective term for deep vein thrombosis (DVT) and pulmonary embolism (PE), is a serious vascular condition associated to high economic and clinical burden. Apixaban, a Novel Oral Anticoagulant (NOAC) has shown non-inferiority efficacy versus the current standard of care (low molecular weight heparin [LMWH]/vitamin K antagonist [VKA]) in the acute treatment and prevention of VTE and a significant reduction in the risk of bleeding.

AIM: Evaluate the economic impact of the use of apixaban for treatment and prevention of DVT and PE from the perspective of the Italian National Health System (NHS).

METHODS: A budget impact model was adapted in order to compare clinical outcomes and economic consequences associated to apixaban vs. LMWH/VKA and others NOACs over a three-year time horizon in the Italian setting. In the analysis two scenario were compared: status quo scenario without apixaban and an alternative scenario with apixaban. Only direct healthcare costs have been considered.

RESULTS: Assuming a population of patients receiving apixaban over the first 3 years equal to 20,957, the introduction of apixaban is associated to an incremental saving of $€ 821,748$ in the first years, $€ 1,250,454$ in the second year, and $€$ $1,866,466$ in the third year. The total net saving over the 3 -year period is $€ 3,938,668$, which is a $2.47 \%$ decrease from the total budget for the status quo scenario without apixaban. This saving is mainly due to reduced VTE events and bleeds by apixaban. Indeed apixaban is associated with less VTE events (both fatal and non-fatal), less major bleeding and less Clinical Relevant Non Major (CRNM) bleeding with a total of 52 fatal events avoided.

CONCLUSIONS: The listing of apixaban for the treatment of VTE (both DVT and PE) and the prevention of recurrent VTE provides both significant clinical advantages, in terms of deaths and events avoided, and economical advantages, consisting in a reduction in the total expenditure on the Italian NHS.
\end{abstract}

\section{Keywords}

Apixaban; Venous thromboembolism; Budget Impact; NOAC

\section{INTRODUCTION}

Venous Thromboembolism (VTE), including pulmonary embolism (PE) and deep vein thrombosis (DVT) is a clinical condition associated with a high morbidity and mortality rate [1]. VTE is the third cause of cardiovascular death, with PE constituting a greater risk than DVT; in fact, 30-day mortality for patients with DVT is around $6 \%$ while for patients with $\mathrm{PE}$ it is around $12 \%$, rising to $17 \%$ within 3 months [2].

The incidence of VTE in the general population is around 70-120 cases/year/100,000 inhabitants (one third of which are cases of PE with or without DVT and two third are cases of DVT) [2-4]. It is estimated that in Italy the incidence rate is 9.6 cases $/ 10,000$ in men and 11.1 cases $/ 10,000$ in women, with a total of around 61,000 cases [5]. In addition to its clinical impact, VTE also involves a heavy financial burden for the NHS (National Health System) due not only to management of the acute episode, but also the management and prevention of long-term complications, such as recurrences of VTE, post-thrombotic syndrome and pulmonary hypertension [1]. The risk of recurrence is particularly high, with a recurrence rate of around $7 \%$ during the first 6 months and increasing to $25 \%$ during the 5 years following the acute episode $[2,6]$. Correct management of VTE must therefore provide not only appropriate, timely treatment of
Corresponding author Marco Bellone m.bellone@adreshe.com

Disclosure

Study funded by BristolMyers Squibb and Pfizer 
the acute episode, but also effective prevention of recurrent events.

The standard treatment for VTE is an initial subcutaneous injection of low molecular weight heparin (LMWH) followed by oral therapy with vitamin $\mathrm{K}$ antagonists (VKA) [7]. The limitations of standard treatment relate to the parenteral administration of LMWH, which is potentially inconvenient in the case of treatment outside of hospital, and factors associated with VKA therapy, which could reduce patient compliance. These factors include interactions with drugs and food, the need for regular International Normalized Ratio (INR) monitoring, followed by the ne-

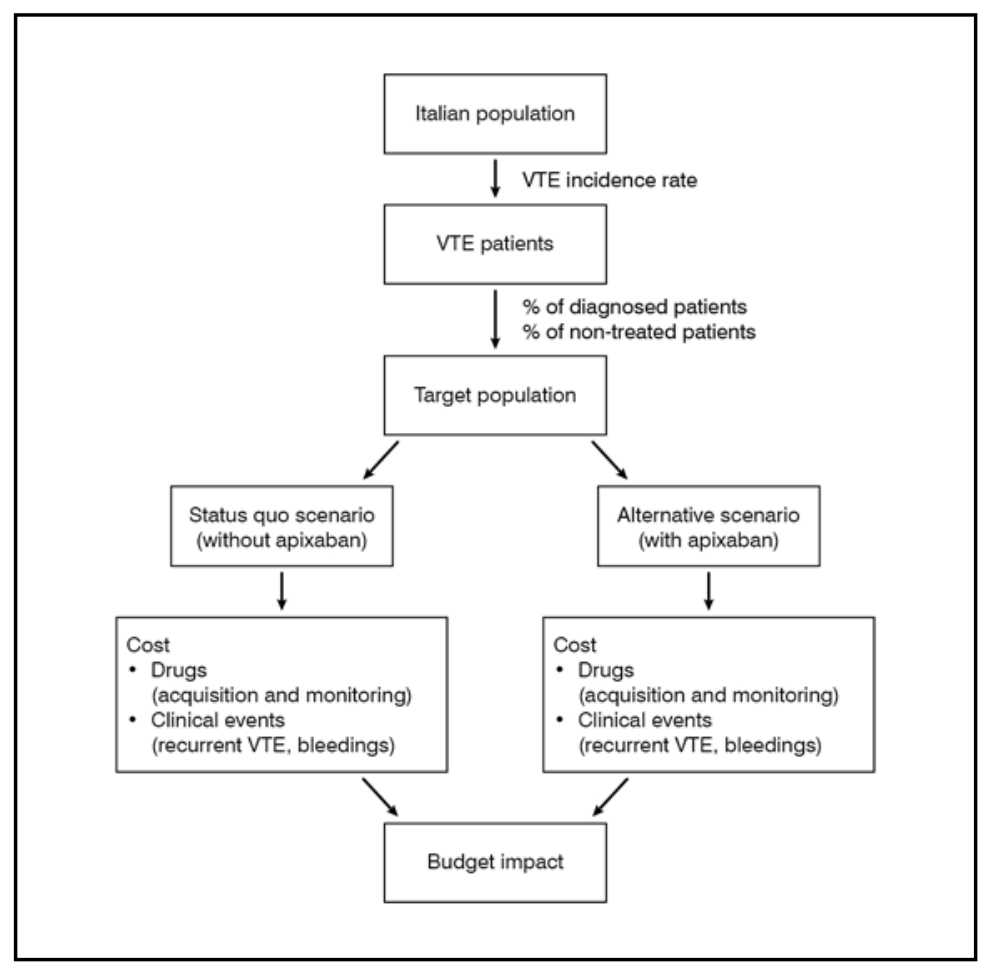

Figure 1. Scheme of the budget impact analysis

\begin{tabular}{lccc}
\hline & Year 1 & Year 2 & Year 3 \\
\hline Population (n.) & $61,178,335$ & $61,423,049$ & $61,668,741$ \\
VTE incidence rate (\%) & & 0.1 & \\
Non-diagnosed patients (\%) & & 30.6 & \\
PE & & \\
- Incidence (\%) & 33.3 & \\
- Non-treated patients (\%) & & 0 & \\
- Treated patients (n.) & 14,157 & 14,214 & 14,271 \\
DVT & & & \\
- Incidence (\%) & & 66.7 & \\
- Non-treated patients (\%) & & 2 & \\
- Treated patients (n.) & 27,748 & 27,859 & 27,971 \\
Total treated patients (n.) & 41,906 & 42,073 & 42,241 \\
\hline
\end{tabular}

Table I. Calculation of the target population over the 3 years of analysis cessary dosage adjustments, and the risk of major bleeds [8].

In order to overcome the limitations associated with LMWH/VKA therapy, new anticoagulant drugs have been developed, which are capable of simplifying even long-term patient management [9]. The novel oral anticoagulants (NOACs) currently available (rivaroxaban, dabigatran, apixaban and edoxaban), indicated in the treatment and prevention of recurrent VTE, have demonstrated similar efficacy and greater safety than the standard treatment, without the need for INR monitoring [10].

In May 2015, apixaban, previously indicated for the prevention of VTE in patients undergoing major orthopaedic surgery and in prevention of stroke and systemic embolism in patients with non-valvular atrial fibrillation, obtained by the AIFA (Agenzia Italiana del Farmaco) approval and reimbursement also for the treatment and prevention of recurrent VTE [11]. Registration of the new indication was supported by the results of AMPLIFY (apixaban vs. enoxaparin/warfarin) [12] and AMPLIFY-EXT (apixaban vs. placebo) [13] multicentre, randomized, double blind, phase III studies.

The purpose of this analysis is to evaluate the impact on the Italian NHS budget of including apixaban in the current treatment mix (LMWH/VKA, rivaroxaban and dabigatran) for the treatment of acute episodes and the prevention of recurrent VTE in Italy.

\section{MATERIALS AND METHODS}

A budget impact model, previously developed but not yet published, was adapted to simulate the economic impact of apixaban vs. LMWH/VKA and others NOACs for treatment and prevention of DVT and PE within an Italian cohort.

The budget impact analysis, performed using an analytical model developed in Microsoft Excel, was conducted from the perspective of the Italian NHS over a 3-year period according to guidelines from ISPOR $[14,15]$.

The financial impact from introducing apixaban into the current prescribing pattern for the treatment and secondary prevention of VTE was estimated by analysing total costs in a cohort of patients with VTE eligible for treatment, and comparing a status quo scenario in which apixaban is not yet available with an alternative scenario following the introduction of apixaban (Figure 1). In particular, costs relating to the acquisition and monitoring of drugs, the treatment of episodes of recurrent VTE and the management of clinical bleeding events (fatal bleeding, intra- 
cranial bleeding - IC, major non-IC and clinical relevant non-major - CRNM bleeding) were considered. Mortality associated with a recurrent VTE event or bleeding has also taken into account.

The estimated eligible population for treatment over the 3 years of analysis was calculated based on natural growth rates [16] using the population of Italy living there on 1st January 2013 and applying a VTE incidence rate of $0.1 \%$, as reported by the study conducted by Cimminiello et al. [5], which retrospectively analysed the data of 372,000 patients of 400 general practitioners between 2001 and 2004. The percentage of patients that is undiagnosed, estimated at $30.6 \%$, was excluded from the incident population. Finally, patients were subdivided based on the diagnosis of PE or DVT $333.3 \%$ and $66.7 \%$, respectively according to epidemiological estimates) and patients thought not to be receiving treatment $(0 \%$ of patients with $\mathrm{PE}$ and $2 \%$ of patients with DVT [Assumption] were excluded. The calculation of the target population is reported in Table I.

\section{Treatment scenarios}

Target patients were divided into the treatment regimens currently approved and prescribed in Italy for the treatment and prevention of VTE: NOACs (apixaban, dabigatran and rivaroxaban) and the standard treatment with LMWH/VKA (enoxaparin/warfarin). Edoxaban was not included as it was not yet available at the time of carrying out the analysis. The percentage distribution of patients into the individual classes of available drugs derives from a simulation of prescription scenarios in which the market share of NOACs is $50 \%, 55 \%$ and $60 \%$ in years 1,2 and 3 , respectively, with the remaining percentages (50\%, $45 \%$ and $40 \%$ ) belonging to $\mathrm{LMWH} /$ VKA.

In the status quo scenario, in which apixaban is not available, the market shares of the NOACs are divided between dabigatran and rivaroxaban, with percentages of $25 \%$ and $75 \%$ of the total market shares of NOACs, respectively.
In the scenario in which apixaban is available, it is estimated that NOACs will represent a greater market share $(60 \%, 65 \%$ and $70 \%)$ than LMWH-VKA $(40 \%, 35 \%$ and $30 \%)$. In the case of apixaban, this is estimated to obtain $15 \%, 25 \%$ and $35 \%$ of prescriptions of NOACs over the three years of analysis. The remaining market shares of NOACs, i.e. $51 \%, 48.75 \%$ and $45.5 \%$, are divided between dabigatran (25\%) and rivaroxaban (75\%). Table II shows the estimated distribution of the different treatment regimens over the three years of analysis for the two scenarios considered.

\section{Clinical events}

The clinical events considered in the analysis include recurrent VTE (including episodes of non-fatal PE, non-fatal DVT and fatal VTE), major bleeding (including fatal bleeding, IC and non-IC bleeding) and CRNM bleeding.

The clinical event onset rates for apixaban comes from the AMPLIFY pivotal trial [12] with regard to the first 6 months following the start of treatment, and the AMPLIFYEXT pivotal trial [13] with regard to months 6-18 post initiation of treatment.

These trials were conducted in order to evaluate the efficacy and safety of apixaban in treating PE and DVT and in preventing recurrent VTE after 6-12 months of treatment. In particular, the AMPLIFY study [12] involved 5,395 patients with an acute episode of VTE who were randomized to receive apixaban $10 \mathrm{mg}$ bid per os for 7 days, followed by 5 apixaban $5 \mathrm{mg}$ bid per os for the next 6 months or enoxaparin $1 \mathrm{mg} / \mathrm{kg}$ bid administered subcutaneously for at least 5 days (until INR > 2) and warfarin per os for 6 months.

The study results demonstrated the noninferiority of apixaban compared with enoxaparin/warfarin in terms of incidence of recurrent fatal and non-fatal VTE (RR: 0.84; CI95\%: 0.60-1.18) and its superiority compared with enoxaparin/warfarin with regard to the primary safety endpoint (major bleeds RR: 0.31; CI95\%: 0.17-0.55). Apixaban also significantly reduced the incidence of composite endpoints comprising major/CRNM

\begin{tabular}{lccc|ccc}
\hline & \multicolumn{2}{c}{ Status quo scenario (without apixaban) } & \multicolumn{3}{c}{ Alternative scenario (with apixaban) } \\
\cline { 2 - 7 } & Year 1 & Year 2 & Year 3 & Year 1 & Year 2 & Year 3 \\
\hline LMWH-VKA (\%) & 50.00 & 45.00 & 40.00 & 40.00 & 35.00 & 30.00 \\
NOACs (\%) & 50.00 & 55.00 & 60.00 & 60.00 & 65.00 & 70.00 \\
- Apixaban & - & - & - & 9.00 & 16.25 & 24.50 \\
- Rivaroxaban & 37.50 & 41.25 & 45.00 & 38.25 & 36.56 & 34.13 \\
- LMWH-dabigatran & 12.50 & 13.75 & 15.00 & 12.75 & 12.19 & 11.37 \\
\hline
\end{tabular}

Table II. Distribution of patient numbers in the scenario with and without apixaban 


\begin{tabular}{|c|c|c|c|c|c|}
\hline & Package & $\begin{array}{l}\text { Ex-factory } \\
\text { price }^{1}(€)\end{array}$ & $\begin{array}{l}\text { Unit cost } \\
(€)\end{array}$ & Induction daily dose & $\begin{array}{l}\text { Prophylactic } \\
\text { daily dose }\end{array}$ \\
\hline Apixaban & 60 tablets 2.5 or $5 \mathrm{mg}$ & 66.97 & 1.12 & 10 mg bid (7 days) & $10 / 5 \mathrm{mg} / \mathrm{die}^{2}$ \\
\hline \multirow[t]{2}{*}{ Rivaroxaban } & 42 tablets $15 \mathrm{mg}$ & 92.57 & 2.20 & 15 mg bid (21 days) & 20 mg/die \\
\hline & 28 tablets $20 \mathrm{mg}$ & 61.71 & & & \\
\hline $\mathrm{LMWH}^{3}$ & $\begin{array}{l}10000 \mathrm{UI} \text { AXA/1 ml solution for } \\
\text { injection } 10 \text { prefilled syringes } 1 \mathrm{ml}\end{array}$ & 66.34 & 6.63 & $1 \mathrm{mg} / \mathrm{kg}$ bid (7,64 days) & - \\
\hline Dabigatran & 60 tablets 150 mg & 66.97 & 1.12 & - & $150 \mathrm{mg}$ bid \\
\hline VKA (warfarin) & 30 tablets $5 \mathrm{mg}$ & $2.17^{4}$ & 0.07 & 5 mg/die (7,64 days) & $5 \mathrm{mg} / \mathrm{die}$ \\
\hline
\end{tabular}

Table III. Daily cost and dosage of treatment with the various alternatives during the induction and prophylaxis phases

${ }^{1}$ The drug acquisition costs were calculated based on hospital sales prices at the net of transitory legal price reductions (temporary reductions referred to AlFA Resolutions of 3/7/2006 and 27/09/2006) and mandatory discounts, estimates on the median of the tender prices

${ }^{2} \mathrm{Apixaban} 5 \mathrm{mg}$ bid is administered for the first 6 months after the induction phase and the dose of $2.5 \mathrm{mg}$ bid is administered thereafter

${ }^{3}$ The cost of LMWH was estimated for a patient with an average weight of $84.6 \mathrm{~kg}$ treated with enoxaparin [12]

${ }^{4}$ Retail price

bleeding (RR: 0.44; CI95\%: 0.36-0.55) and VTE/mortality from VTE/major bleeding (RR: 0.62; CI95\%: 0.47-0.83) [12]. The AMPLIFY-EXT study [13] was designed to determine the efficacy and safety of apixaban in preventing the recurrence of DVT and PE. 2,482 patients were enrolled into the study, having completed 6 to 12 months of anticoagulant therapy. They were randomized to treatment with apixaban $2.5 \mathrm{mg}$ bid, $5 \mathrm{mg}$ bid or placebo for 12 months. Both dosages of apixaban proved superior to the placebo in terms of preventing the recurrence of VTE

\begin{tabular}{|c|c|c|c|c|}
\hline \multirow{2}{*}{ Resource } & \multirow{2}{*}{$\begin{array}{l}\text { Unit cost } \\
(\epsilon)\end{array}$} & \multirow{2}{*}{ Source } & \multicolumn{2}{|c|}{$\begin{array}{l}\text { Frequency of } \\
\text { use (n.) [23] }\end{array}$} \\
\hline & & & DVT & PE \\
\hline \multicolumn{5}{|l|}{ Outpatient treatment } \\
\hline Doppler ultrasound & 43.90 & Cod. 88.77.2 [24] & 1 & 1 \\
\hline CT angiography & 184.80 & Cod. 88.92.2 [24] & 0 & 1 \\
\hline Echocardiogram & 11.62 & Cod. 89.52 [24] & 0 & 1 \\
\hline D-Dimer test & 4.99 & Cod. 90.61 .5 [24] & 1 & 1 \\
\hline Chest X-ray & 15.49 & Cod. 87.44 .1 [24] & 0 & 1 \\
\hline Emergency admission & 270.00 & $\begin{array}{l}\text { Italian Ministry } \\
\text { of Health [25] }\end{array}$ & 1 & 1 \\
\hline \multicolumn{5}{|l|}{ Inpatient treatment } \\
\hline Non-fatal PE & $4,009.00$ & DRG 78 [22] & - & - \\
\hline Non-fatal DVT & $2,315.00$ & DRG 128 [22] & - & - \\
\hline Fatal VTE & $2,315.00$ & DRG 128 [22] & - & - \\
\hline \multicolumn{5}{|l|}{ Bleeding events } \\
\hline IC & $25,812.00$ & DRG 528 [22] & - & - \\
\hline Major non-IC & $3,317.00$ & DRG 174 [22] & - & - \\
\hline CRNM & $2,091.00$ & DRG 175 [22] & - & - \\
\hline Fatal & $3,891.00$ & DRG 14 [22] & - & - \\
\hline
\end{tabular}

Table IV. List of resources used to manage clinical events and the respective sources and in terms of total mortality $(2.5 \mathrm{mg}=\mathrm{RR}$ : 0.33; CI95\%: 0.22-0.48; $5 \mathrm{mg}=\mathrm{RR}: 0.36$; CI95\%: 0.25-0.53), while the incidence of major bleeding was similar in all three treatment groups [13].

In the absence of any study carrying out a direct comparison, the relative risks for the comparators derive from two network metaanalysis that were conducted to compare the efficacy and safety of anticoagulant for the initial, long-term and extended treatment of VTE $[10,17]$. The same risk of clinical event was taken into consideration for all patients who completed the treatment period, regardless of the treatment they received.

\section{Costs}

In order to reflect the NHS's perspective, the analysis only considered health costs directly relating to the acquisition and monitoring of drugs and to the inpatient or outpatient management of episodes of VTE and bleeding events. The cost for the first event of VTE was not taken into account, as it does not generate any differential cost between scenario with and without apixaban.

\section{Drugs}

The drug acquisition costs are drawn from the Italian Official Gazette (OG General Series No. 246 of 22-10-2014). In keeping with current legislation and what is stated by the $\mathrm{OG}$, the direct distribution channel for apixaban, rivaroxaban, dabigatran and LMVH through hospitals (valued using the ex-factory price) and the territorial channel for warfarin (valued using the retail price) were considered. Treatment costs for both induction and prophylactic phase were calculated based on the dosages shown in the SPCs of the drugs (Table III).

The duration of treatment was assumed to be the same for all alternatives in both scenarios 
considered and it was estimated that $40 \%$ of patients remain under treatment for 3 months, $30 \%$ for 6 months, $20 \%$ for 12 months and $10 \%$ for 18 months. The cost of the LMWH injection was not taken into account as it was assumed to be self-administered by all patients.

INR monitoring is only counted in the case of warfarin, and as recommended by the guidelines of the Task Force on Pulmonary Embolism [18], 14 check-ups were taken into account during the first 3 months with 1 check-up/month thereafter. The cost of the check-up was calculated based on the annual cost reported by Mennini et al. [19] and the frequency of monitoring reported by Pengo et al. [20] and was estimated at $€ 23.75$.

\section{Management of clinical events}

The costs associated with managing recurrent VTE were estimated taking into account both inpatient and outpatient treatment. From a prospective study based on data from the MASTER registry, which gathered the data on 25 Italian centres about 2,119 patients suffering an acute episode of VTE, we know that $90.8 \%$ of patients were admitted to hospital after a VTE episode and only the $68.1 \%$ after a DVT episode [21].

In an inpatient setting, the cost per patient for the management of an episode of PE is $€ 4,009$, and it is $€ 2,315$ for an episode of DVT.

The cost of managing an episode of non-fatal $\mathrm{PE}$ and DVT on an outpatient basis was estimated at $€ 530.80$ and $€ 318.89$ respectively. Table IV shows the resources and sources used to estimate the cost and frequency of use. The cost of hospitalization following an episode of VTE comes from the price list for hospital services for acute patients [22], and in particular DRG 78 was used for PE and DRG 128 was used for DVT. The cost of treating an episode of fatal VTE was assumed to be the same as inpatient treatment for DVT (Table IV).
The costs of managing bleeding events were calculated using the price list for hospital care for acute patients [22] (Table IV).

\section{Scenario analysis}

In order to test the robustness of the results obtained and the parameters used in the basecase, several scenario analyses were performed, in which the percentage of patients under treatment for 3, 6, 12 and 18 months was changed. In particular, two different alternative scenarios were examined:

1. All patients treated for 6 months;

2. $30 \%$ of patients treated for 3 months, $30 \%$ for 6 months, $30 \%$ for 12 months and $10 \%$ for 18 months;

Two different scenarios were also examined based on patient distribution:

3. One scenario in which the only NOAC available is apixaban, therefore in the scenario without apixaban all patients are reserved for LMWH-VKA. Following the introduction of apixaban there is an equal distribution of patients (base scenario: $\mathrm{LMWH}-\mathrm{VKA}=100 \%$; alternative scenario: LMWH-VKA $=50 \% /$ Apixaban $=50 \%$ );

4. One scenario in which only NOACs are present, therefore in the scenario without apixaban, patients are divided equally between rivaroxaban and dabigatran. In the alternative scenario $100 \%$ of patients are equally divided between the three NOACs (status quo scenario: rivaroxaban $/$ dabigatran $=50 \% / 50 \%$; alternative scenario: apixaban/rivaroxaban/dabiga$\operatorname{tran}=33.3 \% / 33.3 \% / 33.3 \%$ ).

\section{RESULTS}

Table V shows the number of patients allocated to the different treatment strategies in the two scenarios analyzed in the base-case.

The results of the budget impact analysis show that for an estimated target population eligible for treatment and prevention of VTE of 41,905 patients for the first year, 42,073

\begin{tabular}{|c|c|c|c|c|c|c|}
\hline & \multicolumn{6}{|c|}{ Treated patients (n.) } \\
\hline & \multicolumn{3}{|c|}{ Status quo scenario (without apixaban) } & \multicolumn{3}{|c|}{ Alternative scenario (with apixaban) } \\
\hline & Year 1 & Year 2 & Year 3 & Year 1 & Year 2 & Year 3 \\
\hline Apixaban & 0 & 0 & 0 & 3,771 & 6,837 & 10,349 \\
\hline Rivaroxaban & 15,714 & 17,355 & 19,009 & 16,029 & 15,382 & 14,417 \\
\hline LMWH-dabigatran & 5,238 & 5,785 & 6,336 & 5,343 & 5,129 & 4,803 \\
\hline LMWH-VKA & 20,953 & 18,933 & 16,896 & 16,762 & 14,726 & 12,672 \\
\hline Total & 41,905 & 42,073 & 42,241 & 41,905 & 42,073 & 42,241 \\
\hline
\end{tabular}

Table V. Distribution of patients between the different treatment strategies in both scenarios 


\begin{tabular}{|c|c|c|c|c|c|c|}
\hline & \multicolumn{6}{|c|}{ Costs (€) } \\
\hline & \multicolumn{2}{|c|}{ Year 1} & \multicolumn{2}{|c|}{ Year 2} & \multicolumn{2}{|c|}{ Year 3} \\
\hline & $\begin{array}{l}\text { Status quo } \\
\text { scenario }^{1}\end{array}$ & $\begin{array}{l}\text { Alternative } \\
\text { scenario }^{2}\end{array}$ & $\begin{array}{l}\text { Status quo } \\
\text { scenario }^{1}\end{array}$ & $\begin{array}{l}\text { Alternative } \\
\text { scenario }^{2}\end{array}$ & $\begin{array}{l}\text { Status quo } \\
\text { scenario }^{1}\end{array}$ & $\begin{array}{l}\text { Alternative } \\
\text { scenario }^{2}\end{array}$ \\
\hline Pharmaceutical & $8,988,034$ & $10,599,151$ & $10,503,633$ & $12,335,721$ & $11,381,600$ & $13,310,314$ \\
\hline INR monitoring & $8,746,631$ & $6,997,305$ & $8,198,914$ & $6,383,498$ & $7,320,371$ & $5,497,694$ \\
\hline Recurrent VTE events & $7,946,260$ & $7,924,638$ & $16,077,039$ & $16,044,535$ & $24,501,867$ & $24,453,720$ \\
\hline Bleeding events & $14,668,311$ & $14,006,394$ & $18,946,554$ & $17,711,932$ & $22,345,958$ & $20,421,602$ \\
\hline Total & $40,349,236$ & $39,527,488$ & $53,726,140$ & $52,475,686$ & $65,549,796$ & $63,683,330$ \\
\hline Budget impact & \multicolumn{2}{|c|}{$-821,748$} & \multicolumn{2}{|c|}{$-1,250,454$} & \multicolumn{2}{|c|}{$-1,866,466$} \\
\hline
\end{tabular}

Table VI. Results of the budget impact analysis over three years

${ }^{1}$ Without apixaban

${ }^{2}$ With apixaban

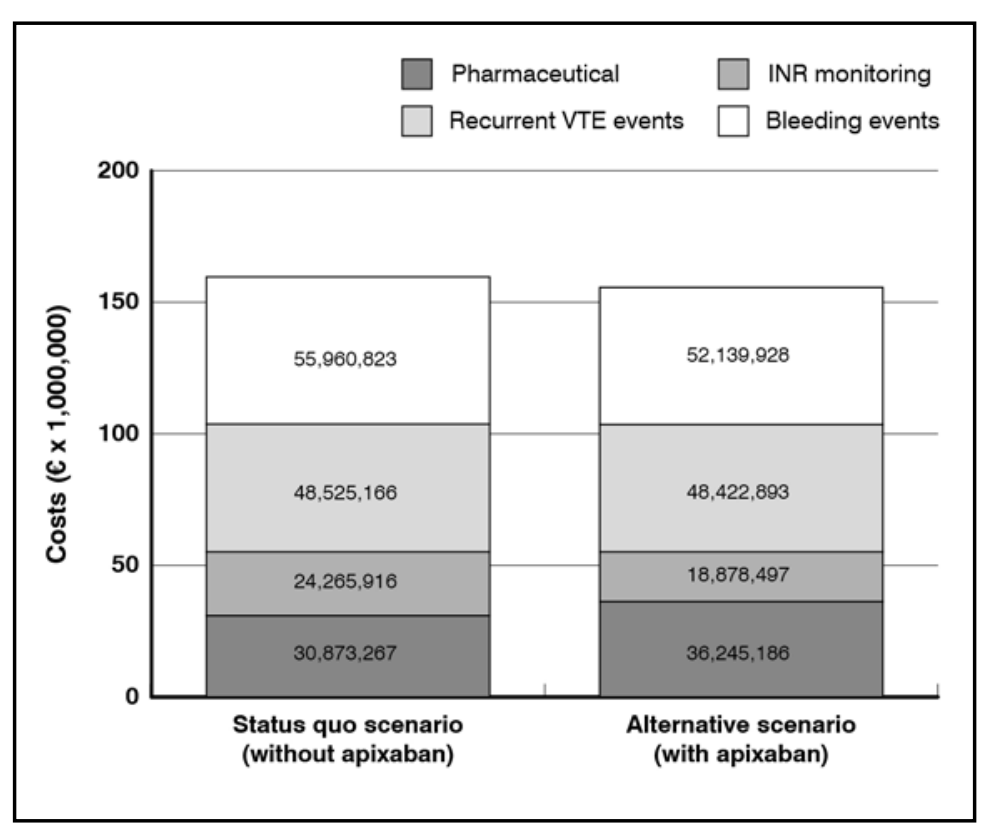

Figure 2. Results of the cumulative budget impact analysis over three years for the second year and 42,241 patients for the third year, the introduction of apixaban into the current combination therapy for VTE, with annually increasing percentages of use, would mean a potential saving for the Italian NHS of $€ 821,748, € 1,250,454$ and $€$ $1,866,466$ in the course of the first, second and third year of treatment, respectively (Table VI).

Figure 2 shows the cumulative results of the budget impact analysis for 3 year, resulting in a total saving for the Italian NHS of $€$ $3,938,668$, due to the use of apixaban over a three-year period.

Table VII shows the annual cost per patient for the various treatment options considered in the analysis.

Table VIII shows the clinical events (episodes of recurrent fatal and non-fatal VTE) and major bleedings in both treatment scenarios

\begin{tabular}{lccccc}
\hline & \multicolumn{3}{c}{ Costs $(\mathbf{E} / \mathbf{p t s})$} \\
\cline { 2 - 5 } & Pharmaceutical & INR monitoring & Recurrent VTE events & Bleeding events & Total \\
\hline Year 1 & & & & & \\
Apixaban & 418.96 & 0.00 & 183.96 & 176.43 & $3,137.25$ \\
Rivaroxaban & 389.38 & 0.00 & 187.54 & 380.81 & $3,315.63$ \\
LMWH-dabigatran & 418.64 & 0.00 & 195.64 & 251.50 & $3,223.70$ \\
LMWH-VKA & 32.27 & 417.44 & 189.68 & 351.59 & $3,348.88$ \\
Year 2 & & & & 220.50 & $3,308.75$ \\
Apixaban & 439.16 & 0.00 & 291.22 & 501.39 & $3,671.18$ \\
Rivaroxaban & 422.34 & 0.00 & 389.54 & 340.71 & $3,551.84$ \\
LMWH-dabigatran & 456.32 & 0.00 & 396.92 & 458.02 & $3,692.37$ \\
LMWH-VKA & 33.71 & 433.50 & 409.22 & & $3,444.32$ \\
Year 3 & & & & 257.98 & $3,988.89$ \\
Apixaban & 443.16 & 0.00 & 385.30 & 591.79 & $3,869.29$ \\
Rivaroxaban & 423.13 & 0.00 & 616.08 & 430.46 & $4,067.59$ \\
LMWH-dabigatran & 457.23 & 0.00 & 623.71 & 564.41 & \\
LMWH-VKA & 33.74 & 433.83 & 677.72 & & \\
\hline
\end{tabular}

Table VII. Annual costs per patient for the various treatment options considered 
over the three years of analysis. The introduction of apixaban make it possible to avoid 36 new episodes of VTE (including 11 fatal episodes), 302 major bleeding events (including 41 fatal events) and 944 CRNM bleeding events, making a total of 1,282 fewer events over the course of three years.

\section{Scenario analysis}

Tables IX and $X$ and Figure 3 show the results of the scenario analysis.

\section{DISCUSSION}

In recent years NOACs have become an important alternative to the standard therapy employed to treat acute episodes and prevent recurrent VTE. Although LMWH/VKA is still widely used in this setting, their good efficacy and safety profile and practicality have enabled the NOACs to gain large numbers of patients. Apixaban, a reversible, direct selective factor Xa inhibitor is an oral anticoagulant indicated in the treatment and prevention of recurrent DVT and PE. Like the other drugs in its class it presents some benefits with regard to standard treatment: no INR monitoring is necessary, the use of a fixed dosage, the lack of significant interactions with food and infrequent drug interactions. Moreover, like rivaroxaban, but unlike dabigatran, it does not require initial treatment with LMWH. The AMPLIFY study demonstrated the non-inferiority of apixaban to LMWH/ VKA with regard to the primary endpoint of efficacy, and its superiority with regard to the primary endpoint of safety; the AMPLIFYEXT study demonstrated that apixaban has a favourable profile in preventing the recurrence of VTE compared with placebo, with a similar major bleeding rate $[12,13]$. In the absence of direct comparative studies, some network meta-analyses have shown that apixaban is associated with a lower incidence

\begin{tabular}{|c|c|c|c|}
\hline & \multicolumn{3}{|c|}{ Clinical events (n.) } \\
\hline & $\begin{array}{l}\text { Status quo } \\
\text { scenario' }^{1}\end{array}$ & $\begin{array}{l}\text { Alternative } \\
\text { scenario }^{2}\end{array}$ & Avoided \\
\hline VTE & 20,747 & 20,711 & 36 \\
\hline - Non-fatal PE & 5,862 & 5,844 & 17 \\
\hline - Non-fatal DVT & 11,878 & 11,870 & 8 \\
\hline • Fatal VTE & 3,007 & 2,997 & 11 \\
\hline Major bleeding & 4,189 & 3,887 & 302 \\
\hline$\cdot I C$ & 506 & 470 & 37 \\
\hline - Non-IC & 3,119 & 2,894 & 225 \\
\hline - Fatal & 564 & 523 & 41 \\
\hline CRNM & 14,514 & 13,570 & 944 \\
\hline
\end{tabular}

Table VIII. Clinical events over the three-year period in both treatment scenarios ${ }^{1}$ Without apixaban

${ }^{2}$ With apixaban

\begin{tabular}{lccc}
\hline \multicolumn{4}{c}{ Costs $(\boldsymbol{\epsilon})$} \\
\hline $\begin{array}{c}\text { Status quo } \\
\text { scenario }\end{array}$ & $\begin{array}{c}\text { Alternative } \\
\text { scenario }^{2}\end{array}$ & $\begin{array}{c}\text { Budget } \\
\text { impact }\end{array}$ & $\begin{array}{c}\text { Difference in budget } \\
\text { impact: vs. base-case }\end{array}$ \\
\hline $\begin{array}{l}\text { Base-case } \\
159,625,170\end{array}$ & $155,686,505$ & $-3,938,665$ & - \\
Scenario (a) - All patients treated for $\mathbf{6}$ months & \\
$143,562,978$ & $139,858,168$ & $-3,704,810$ & $+233,855$ \\
Scenario (b) - Treatment 3-6-12-18 months: $\mathbf{3 0} \% / \mathbf{3 0} \% / \mathbf{3 0} \% / \mathbf{1 0} \%$ \\
$164,783,102$ & $160,736,028$ & $-4,047,074$ & $-108,406$ \\
\hline
\end{tabular}

Table IX. Results of the scenario analysis relating to duration of treatment ${ }^{1}$ Without apixaban

${ }^{2}$ With apixaban

\begin{tabular}{cccc}
\hline \multicolumn{4}{c}{ Costs $(\boldsymbol{\epsilon})$} \\
\hline $\begin{array}{c}\text { Status quo } \\
\text { scenario }\end{array}$ & $\begin{array}{c}\text { Alternative } \\
\text { scenario }^{2}\end{array}$ & $\begin{array}{l}\text { Budget } \\
\text { impact }\end{array}$ & $\begin{array}{c}\text { Budget impact/ } \\
\text { patient }\end{array}$ \\
\hline Scenario (c) - LMWH-VKA $=\mathbf{1 0 0} \%$ & - LMWH-VKA/apixaban $=\mathbf{5 0 \% / 5 0 \%}$ \\
$162,083,429$ & $149,129,222$ & $-12,954,207$ & -103 \\
Scenario (d) - NOACs & $=\mathbf{5 0} \% / \mathbf{5 0} \%$ & - NOACs $=\mathbf{3 3 . 3} \% / \mathbf{3 3 . 3} \% / \mathbf{3 3 . 3} \%$ \\
$154,291,017$ & $148,250,867$ & $-6,040,150$ & -48 \\
\hline
\end{tabular}

Table $\mathbf{X}$. Results of the scenario analysis relating to patient distribution 1 Without apixaban

${ }^{2}$ With apixaban

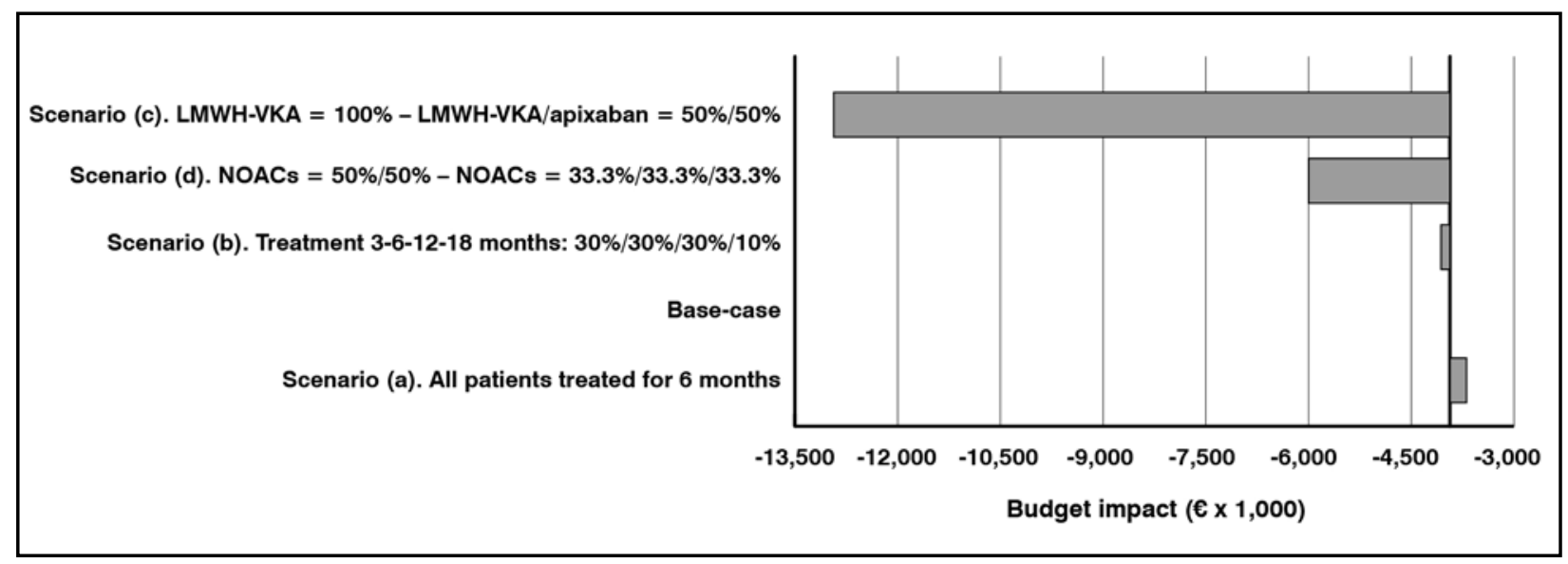

Figure 3. Results of the scenario analysis 
of major bleeding than the other NOACs in the acute treatment of VTE $[10,26]$.

The current guidelines of the American College of Chest Physicians (ACCP), published in 2016, suggest that the NOACs (dabigatran, rivaroxaban, apixaban and edoxaban) be given preference over conventional therapy in the acute treatment of VTE in non-neoplastic patients [9]. A Technology Appraisal published in June 2015 by the National Institute for Health and Clinical Excellence (NICE) recommends apixaban among the options for the treatment and secondary prevention of PE and DVT, also due to the favorable cost-efficacy ratio that it has demonstrated compared with warfarin in the UK setting [27].

The financial benefit of apixaban has been confirmed by the results of this budget impact analysis, in which the introduction of apixaban in the current mix of treatments for VTE is associated with a saving for the Italian NHS in terms of direct health costs relating to the treatment of recurrent VTE and bleeding episodes. In particular, if apixaban were to acquire $15 \%, 25 \%$ and $35 \%$ of the market shares of the NOACs, the saving for the NHS would amount to $€ 821,748$, $€ 1,250,454$ and $€ 1,866,466$ in the first, second and third year following its introduction, respectively, meaning a total saving of $€ 3,938,668 \mathrm{du}-$ ring the first three years of its use. The use of apixaban has also been associated with a reduction in the number of episodes of fatal and non-fatal recurrent VTE, major bleeding and CRNM bleeding, with a total of 52 fatal events avoided in three years.

As for all the economic evaluations, also in this analysis there are some limitations resulting from the assumptions adopted in the development of the model, which may be affected by uncertainty. In the absence of RCTs that directly compare apixaban with other NOACs, relative risks derive from network meta-analysis [10,17], which is a type of analysis widely used in pharmacoeconomics evaluation [28] for overcoming the lack of head-to-head trials. Some credibility intervals of RRs obtained from the Bayesian fixed-effect network meta-analysis cross 1: in the classic interpretation of frequentist statistics they would be considered as not significant. However, the classical interpretation of statistical significance may not be applied directly to the Bayesian credibility interval, which indicates a plausible range of values [29]. Nevertheless, a sensitivity analysis in which these RR values are put equal to 1 (apixaban and comparators have the same event risk) has been performed, showing a $10 \%$ reduction of the savings at the year 3 . However, the base-case analysis is to be considered conservative owing to the prudence of the assumptions made by the Authors: specifically, the inclusion of apixaban in the therapeutic arsenal for managing VTE determines an increase in treatment with NOACs compared with standard treatment (as assumed in the scenario with apixaban, in which the category of NOACs gains $+10 \%$ of patients compared with the status quo scenario), which at the same time favors the entire category, also allowing dabigatran and rivaroxaban to gain patient numbers compared with the scenario without apixaban. This dynamic, known in microeconomics as the "knock-on benefit", according to which the distribution of one product favors an increase in sales of the entire category, influences savings during the first year of analysis: specifically, patients treated with rivaroxaban and dabigatran are associated with higher VTE management costs than they would have been if all the patients gained in the category of NOACs had been under treatment with apixaban.

Finally, the results of the scenario analyses confirmed the results of the budget impact analysis, suggesting the potentially greater benefit of apixaban when treatment is extended beyond 6 months. The scenario in which the percentages of patients under treatment for $3,6,12$ and 18 months are equal to $30 \%$, $30 \%, 30 \%$ and $10 \%$, respectively, actually further increased the saving achieved in the base-case by $€ 108,406$. Finally, the scenario analyses performed by modifying patient distribution also confirmed the benefit associated with apixaban, both in the case where patient numbers were shared only between the NOACs $(B I=-6,040,150 €)$ and in the case where numbers were shared equally with LMWH/VKA $(\mathrm{BI}=-12,954,207 €)$.

\section{CONCLUSIONS}

The inclusion of apixaban in the current mix of available treatments for acute episodes of VTA and the prevention of recurrent VTE is associated with clinical benefits in terms of reducing recurrent fatal and non-fatal VTE events and bleeding episodes, and financial benefits in terms of impact on the budget of the Italian NHS. 


\section{REFERENCES}

1. Dobesh PP. Economic burden of venous thromboembolism in hospitalized patients. Pharmacotherapy 2009; 29: 943-53; http://dx.doi.org/10.1592/phco.29.8.943

2. White RH. The epidemiology of venous thromboembolism. Circulation 2003; 107: I4-I8; https://doi.org/10.1161/01. CIR.0000078468.11849.66

3. Spencer FA, Emery C, Lessard D, et al. The Worchester Venous Thromboembolism Study. A population-based study of the clinical epidemiology of venous thromboembolism. J Gen Intern Med 2006; 21: 722-7; https://doi. org/10.1111/j.1525-1497.2006.00458.x

4. Silverstein MD, Heit JA, Mohr DN, et al. Trends in the incidence of deep vein thrombosis and pulmonary embolism: a 25-year population-based study. Arch Intern Med 1998; 158: 585-93; https://doi.org/10.1001/archinte.158.6.585

5. Cimminiello C, Filippi A, Mazzaglia G, et al. Venous thromboembolism in medical patients treated in the setting of primary care: a nationwide case-control study in Italy. Thromb Res 2010; 126: 367-72; https://doi.org/10.1016/j. thromres.2010.07.005

6. Prandoni P. Treatment of patients with acute deep vein thrombosis and/or pulmonary embolism: efficacy and safety of non-VKA oral anticoagulants in selected populations. Thromb Res 2014; 134: 227-33; https://doi.org/10.1016/j. thromres.2014.05.013

7. Kearon C, Akl EA, Comerota AJ, et al. American College of Chest Physicians. Antithrombotic therapy for VTE disease: Antithrombotic Therapy and Prevention of Thrombosis, 9th ed: American College of Chest Physicians Evidence-Based Clinical Practice Guidelines. Chest 2012; 141(2 Suppl): 419-94; http://dx.doi.org/10.1378/chest.11-2301

8. Ansell J, Hirsh J, Hylek E, et al.; American College of Chest Physicians. Pharmacology and management of the vitamin K antagonists: American College of Chest Physicians Evidence-Based Clinical Practice Guidelines (8th Edition). Chest 2008; 133(6 Suppl): 160S-198S; https://doi.org/10.1378/chest.08-0670

9. Kearon C, Akl EA, Ornelas J, et al. Antithrombotic Therapy for VTE Disease: CHEST Guideline and Expert Panel Report. Chest 2016; 149: 315-52; https://doi.org/10.1016/j.chest.2015.11.026

10. Cohen AT, Hamilton M, Mitchell SA, et al. Comparison of the Novel Oral Anticoagulants Apixaban, Dabigatran, Edoxaban, and Rivaroxaban in the Initial and Long-Term Treatment and Prevention of Venous Thromboembolism: Systematic Review and Network Meta-Analysis. PLoS One 2015; 10: e0144856; https://doi.org/10.1371/journal. pone. 0144856

11. Comunicato relativo al medicinale per uso umano «Eliquis» (15A03834). GU Serie Generale n.118 del 23-5-2015

12. Agnelli G, Buller HR, Cohen A, et al.; AMPLIFY Investigators. Oral apixaban for the treatment of acute venous thromboembolism. N Engl J Med 2013; 369: 799-808; https://doi.org/10.1056/NEJMoa1302507

13. Agnelli G, Buller HR, Cohen A, et al.; AMPLIFY-EXT Investigators. Apixaban for extended treatment of venous thromboembolism. N Engl J Med 2013; 368: 699-708; https://doi.org/10.1056/NEJMoa1207541

14. Mauskopf JA, Sullivan SD, Annemans L, et al. Principles of good practice for budget impact analysis: report of the ISPOR Task Force on good research practices--budget impact analysis. Value Health 2007; 10: 336-47; https:// doi.org/10.1111/j.1524-4733.2007.00187.x

15. Sullivan SD, Mauskopf JA, Augustovski F, et al., Budget impact analysis-principles of good practice: report of the ISPOR 2012 Budget Impact Analysis Good Practice II Task Force. Value Health 2014; 17: 5-14; https://doi. org/10.1016/j.jval.2013.08.2291

16. ISTAT - Istituto Nazionale di Statistica. Available at: http://dati.istat.it/Index.aspx (last accessed April 2016)

17. Cohen AT, Hamilton M, Bird A, et al. Comparison of the Non-VKA Oral Anticoagulants Apixaban, Dabigatran, and Rivaroxaban in the Extended Treatment and Prevention of Venous Thromboembolism: Systematic Review and Network Meta-Analysis. PLoS One 2016; 11: e0160064; https://doi.org/10.1371/journal.pone.0160064

18. Task Force sull'Embolia Polmonare. Linee guida per la diagnosi ed il trattamento dell'embolia polmonare acuta. Ital Heart J Suppl 2001; 2: 161-99

19. Mennini F, Russo S, Marcellusi A. Budget impact analysis resulting from the use of dabigatran etexilate in preventing stroke in patients with non-valvular atrial fibrillation in Italy. Farmeconomia. Health economics and therapeutic pathways 2012;13: 121-31; https://doi.org/10.7175/fe.v13i3.268

20. Pengo V, Crippa L, Falanga A, et al. Questions and answers on the use of dabigatran and perspectives on the use of other new oral anticoagulants in patients with atrial fibrillation. A consensus document of the Italian Federation of Thrombosis Centers (FCSA). ThrombHaemost 2011; 106: 868-76; https://doi.org/10.1160/TH11-05-0358 
21. Agnelli G, Verso M, Ageno W, et al.; MASTER investigators. The MASTER registry on venous thromboembolism: description of the study cohort. Thromb Res 2008; 121: 605-10; https://doi.org/10.1016/j.thromres.2007.06.009

22. Tariffe delle prestazioni di assistenza ospedaliera per acuti (sistema DRG). Supplemento ordinario n. 8 alla Gazzetta Ufficiale Serie generale - n. 23 del 28-1-2013

23. Torbicki A, Perrier A, Konstantinides S, et al.; ESC Committee for Practice Guidelines (CPG). Guidelines on the diagnosis and management of acute pulmonary embolism: the Task Force for the Diagnosis and Management of Acute Pulmonary Embolism of the European Society of Cardiology (ESC). Eur Heart J2008; 29: 2276-315; https:// doi.org/10.1093/eurheartj/ehn310

24. Nomenclatore tariffario dell'assistenza specialistica ambulatoriale. Tariffa Unica Convenzionale. Edizione 2013

25. Ministero della Salute. Progetto Mattoni SSN. Pronto Soccorso e Sistema 118. "Proposta metodologica per la valutazione dei costi dell'emergenza" Roma 2007

26. Castellucci LA, Cameron C, Le Gal G, et al. Efficacy and safety outcomes of oral anticoagulants and antiplatelet drugs in the secondary prevention of venous thromboembolism: systematic review and network meta-analysis. $B M J$ 2013; 347: f5133; https://doi.org/10.1136/bmj.f5133

27. National Institute for Health and Care Excellence. Final Appraisal determination - Apixaban for the treatment and secondary prevention of deep vein thrombosis and/or pulmonary embolism. Technology appraisal guidance [TA341]. Available at: https://www.nice.org.uk/guidance/ta341 (last accessed April 2016)

28. Jansen JP, Fleurence R, Devine B, et al. Interpreting indirect treatment comparisons and network meta-analysis for health-care decision making: report of the ISPOR Task Force on Indirect Treatment Comparisons Good Research Practices: part 1. Value Health 2011; 14: 417-28; https://doi.org/10.1016/j.jval.2011.04.002

29. Spiegelhalter DJ, Abrams KR, Myles JP. Bayesian Approaches to Clinical Trials and Health-Care Evaluation. Hoboken, NJ: Wiley, 2004 